\title{
O sucesso estratégico depende da comunicação
}

\author{
Gilberto Gomes Guedes' \\ Manoel Henrique Tavares Moreira²
}

\section{Resumo}

O presente artigo reúne a visão de um profissional de Gestão da Comunicação e de um especialista em Planejamento Estratégico a respeito da importância de alinhar o Planejamento em Comunicação ao Planejamento Estratégico da Organização. Nele são discutidas questões fundamentais acerca do papel que a comunicação desempenha no processo de planejamento estratégico das organizações modernas e que contribuições o gestor estratégico pode obter da área de Comunicação Organizacional. Dessa forma, discute-se a maneira como o fluxo de informações é gerenciado no interior das organizações e de que forma isso ajuda a fazer com que todos os seus integrantes percebam os elementos de sustentação da estratégia adotada, contribuindo para que sejam assimilados e incorporados à cultura da instituição.

Palavras-chave: Comunicação estratégica. Gestão estratégica da comunicação. Planejamento estratégico em comunicação.

\section{Introdução}

Que papel a comunicação desempenha no processo de planejamento estratégico das organizações modernas? Que contribuições o gestor estratégico pode obter da área de comunicação organizacional? Como gerenciar o fluxo de informações e

\footnotetext{
${ }^{1}$ Gilberto Gomes Guedes - Mestre em Engenharia da Produção, Especialista em Teorias da Administração, docente na área de Administração desde 1983, ministrando as disciplinas “Teoria Geral da Administração", "Gestão de Pessoas", “Teoria Geral de Sistemas”. Atualmente é professor do curso de Administração do UniCEUB.

${ }^{2}$ Manoel Henrique Tavares Moreira - Mestre em Comunicação Social, Especialista em Administração, docente na área de Comunicação desde 1987, ministrando as disciplinas “Telejornalismo", "Projetos de TV", "Assessoria de Imprensa" e "Comunicação Organizacional”. Atualmente é professor e coordenador do curso de Comunicação Social do UniCEUB.
} 
fazer com que os elementos de sustentação da estratégia adotada sejam percebidos, assimilados e incorporados à cultura da instituição? São essas as questões centrais que levaram um administrador e um comunicador a buscarem os indícios que facilitem e integrem o trabalho de quem planeja e de quem divulga o planejamento.

Para muita gente, o conceito de estratégia é algo abstrato, longínquo e que tem relação com o futuro. E o futuro é uma perspectiva de continuidade da organização, de sequência das atividades que desempenha e dos serviços e dos benefícios que representam tanto para a sociedade que a abriga quanto para seus colaboradores e acionistas. Quando essa continuidade é ameaçada pela turbulência ambiental, faz-se necessário adotar uma postura estratégica que oriente a empresa para o longo prazo.

Não obstante, estratégia é ação, é a administração dos recursos presentes e, portanto, constroi-se essencialmente sobre as tomadas de decisão.

Ansoff (1991) destaca inicialmente o planejamento e, posteriormente a administração estratégica, como processos estruturados para a formulação e para a formalização de estratégias.

Hamel e Prahalad (1997) apontam a geração de estratégias como aspectos prioritários para o aumento da competitividade.

O estabelecimento de estratégias concentra-se em identificar para onde as organizações devem ir. Mas, o que pode ser observado é que não se prioriza de maneira adequada a forma de divulgação da informação (comunicação), inerente às etapas de estabelecimento. E ele, necessariamente, depende da qualidade da comunicação.

Negociar o acesso à questão da comunicação da estratégia pode ser semelhante a andar por um labirinto. Sem um plano, a probabilidade de se conseguir acertar o caminho é pequena. Conforme Barreto (2002), esse plano deve possuir cinco princípios:

1 Uma linguagem estratégica em comum;

2 Simplicidade/especificidade;

3 Teste de compreensão;

4 Repetição; e

5 Relevância. 


\section{Uma linguagem estratégica em comum}

Para que possamos adotar uma linguagem estratégica em comum, é necessário desenvolver um processo estratégico, ou seja, uma sequência de etapas para a coleta e a análise de informações. A base do processo estratégico empregado pelas organizações envolve: análise de ambiente, crenças básicas, força propulsora, impulso para o desenvolvimento de novos negócios, futura ênfase e escopo do produto/mercado, teste da realidade, posicionamento, planejamento da ação, questões críticas, indicador-chave e monitoramento.

$\mathrm{O}$ uso de uma linguagem em comum proporciona vantagens especiais às organizações, com um grande número de negócios diversificados. Em tais organizações, talvez seja difícil obter-se unidade e coerência estratégica.

Uma linguagem em comum, como expressa no processo estratégico, não oferece uma solução imediata aos conflitos comuns, mas ajuda na discussão e no debate de ideias.

\subsection{Simplicidade/especificidade}

Para o sucesso na implementação da estratégia, é preciso manter a simplicidade dela, para que todos possam realmente compreendê-la e aplicá-la.

A estratégia deve ser simples e específica o suficiente, para ser levada na cabeça de todo o corpo funcional da organização.

\subsection{Teste da compreensão}

Se após a comunicação da estratégia, o comportamento da comunidade refletir a estratégia, podemos concluir que conseguimos comunicá-la. A ação confirma a compreensão. Porém a ação também pode ser uma prova do fracasso da transmissão da estratégia. Isso pode ser uma forma mais cara de se descobrir que o esforço da comunicação não deu certo.

Uma alternativa mais prática envolve o teste da compreensão da estratégia por uma pessoa ou grupo antes de iniciar a ação. O teste da compreensão consiste 
em pedir às outras pessoas que interpretem a estratégia com suas próprias palavras ou discutam como esta seria aplicada à sua própria área ou como seria aplicada a um exemplo hipotético. Isso aumenta a probabilidade de compreensão e de ação correspondentes às expectativas estratégicas.

\subsection{Repetição}

Pressupor que a estratégia é bem compreendida pode ser fatal para a saúde estratégica da empresa. A repetição é um bom antídoto.

Algumas organizações descobriram que o melhor caminho ainda é adotar um velho método: repita quantas vezes puder a estratégia.

\subsection{Relevância}

Quando se acha que a mensagem estratégica é razoável e importante, a força da relevância está ao lado da empresa.

Para tornar a estratégia relevante, as organizações devem basear sua abordagem na premissa prática de que a educação começa com o indivíduo e onde ele se encontra em um determinado momento.

\section{A gestão estratégica da comunicação}

Por que as organizações contemporâneas valorizam tanto a Comunicação? Por que a Comunicação ocupa espaço tão importante nas estratégias organizacionais? São perguntas que gestores e comunicadores têm de responder com frequência cada vez maior. Entender a relação entre gestão organizacional eficiente e utilização competente da comunicação é fundamental para gerar e manter o que as organizações têm de mais valioso: a reputação.

Não é mais permitido às organizações confiar unicamente na tradição para manter sua posição no mercado. Para o sociólogo italiano Gianfranco Pecchinenda (2005), é cada vez mais comum presenciarmos “a interrupção tipicamente moderna - do processo que cria, no indivíduo, a tradição", algo que 
lhe retira a capacidade de utilizar-se das experiências individuais relacionandoas com a memória coletiva. Com isso, estratégias específicas de comunicação são imprescindíveis para, principalmente, promover "experiências" que ajudem os indivíduos a formar opiniões, despertar interesses e gerar decisões.

Essa condição alterou profundamente o papel e o alcance das ações de comunicação nos ambientes organizacionais. Não é mais possível manter estruturas (cada vez mais caras e complexas) para, unicamente, vigiar o ambiente interno, levantando demandas, tentando reduzir conflitos ou se esforçando desesperadamente para aumentar a motivação entre os públicos estratégicos.

É preciso ir muito além: gerar um conjunto de ações, produtos e estratégias de comunicação com a intenção de agregar valor à marca, consolidar a imagem e promover valores e crenças que atribuam uma identidade à organização. Essa tarefa é complexa demais para ser realizada a partir de ações isoladas, iniciativas solitárias ou afastadas da realidade organizacional. Promover ações integradas de comunicação é a única saída.

A chamada Comunicação Integrada surgiu como resposta a essa necessidade específica das organizações modernas na produção de ações articuladas, visando ultrapassar as barreiras setoriais, os nichos de competência de cada uma das áreas da comunicação, zelosamente defendidos por seus respectivos profissionais. Pensava-se que, dessa forma, combatia-se o individualismo, a visão estreita, o desperdício, enfim, a incompetência.

Mas não se vence um inimigo tão teimoso apenas com boa intenção. É preciso ir além. Não basta querer implantar a filosofia e os programas de Comunicação Integrada. É necessário forçar a mão e quebrar alguns paradigmas. Para tanto, é fundamental atribuir à comunicação um valor estratégico, algo que começa pelo próprio planejamento das ações de comunicação.

Cada vez mais, a comunicação ganha status de consultoria estratégica, que se desenvolve por meio de funções de orientação, de leitura do meio ambiente, de interpretação de cenários e de assessoria aos sistemas decisórios, principalmente em momentos de crise (TORQUATO, 2002, p. 35). 
Planejar estrategicamente a comunicação é o primeiro e o mais importante passo nesse processo de mudança cultural. Nós, comunicadores, principalmente os mais antigos (aqueles que hoje ocupam os postos de direção e chefia), não temos, com raríssimas e honrosas exceções, o saudável hábito de atribuir às atividades de planejamento o mesmo valor que damos à produção de conteúdos, por exemplo. Costumamos fazer intuitivamente ("meio que na marra") aquilo que julgamos ser o mais apropriado para cada situação, sem o cuidado que se espera de um gestor que responde pela destinação de recursos consideráveis.

Fazer comunicação organizacional custa caro. Por isso é proibido errar. As organizações esperam retorno de cada centavo investido em ações de comunicação (seja nas relacionadas à promoção, ao marketing e naquelas que têm como destinatário os stakeholders, os públicos estratégicos). Para não errar, é preciso planejar. E planejar direito.

Uma característica predominante nas organizações pós-modernas é a capacidade de adaptação, de promover mudanças rápidas que permitam confrontar a competição, cada vez mais acirrada. Mais do que mudar, é preciso antecipar-se às mudanças, ter uma atitude pró-ativa para, assim, garantir níveis adequados de competitividade. Por isso, planejar cada uma das atividades é fundamental.

Planejar é conhecer e entender o contexto; é saber o que se quer e como atingir os objetivos; é saber como se prevenir; é calcular os riscos e buscar minimizá-los; é preparar-se taticamente; é ousar as metas propostas e superar-se de maneira contínua e constante. Planejar não é só vislumbrar o futuro, mas é também uma forma de assegurar a sobrevivência e a continuidade dos negócios (CHIAVENATO; SAPIRO, 2003, p. 9-10).

A comunicação tem, portanto, importância fundamental para a gestão da organização e de seus resultados. Todas as ações, eventos, planos e estratégias desenvolvidas pela comunicação devem estar perfeitamente adequados às ações, planos e estratégias da organização como um todo. Por isso, é importante que o gestor comunicador conheça e participe da formulação do plano estratégico da organização, o que lhe dará segurança para definir o rumo da comunicação.

Nesse contexto, em que a visão estratégica é fundamental para manter as condições de competitividade e eficiência organizacionais, é preciso dotar a 
comunicação de uma estrutura sistêmica, integrada, pró-ativa, capaz de responder aos enormes desafios impostos pela modernidade: informação em tempo real, terceirização, mão de obra temporária, aproximação com fornecedores, parcerias com clientes, alianças entre concorrentes etc.

As fronteiras organizacionais se tornam indefinidas, surgem estruturas livres de barreiras e ainda outras totalmente virtuais. Identificar corretamente os fluxos de informação nessas condições é por si só, uma tarefa árdua. Estabelecer ações que consigam resultados diante de tamanha diversidade de estrutura e de interesses constitui-se numa verdadeira façanha. Tudo isso reduz, e muito, a possibilidade de uma gestão eficaz da comunicação baseada, unicamente, na intuição ou no conhecimento empírico, ou pior, somente na experiência do gestor.

Devemos considerar ainda as peculiaridades das atividades da comunicação. São características únicas que as diferenciam dos demais setores da organização. A relação com o tempo (sempre um inimigo), os questionamentos éticos (transparência versus inteligência organizacional) e a ação que busca resultado no comportamento humano são desafios constantes para aqueles que trabalham na área.

\section{Conclusão}

O tratamento da informação vem assumindo grande importância, devido à sua capacidade de alavancar novas vantagens competitivas, não só no levantamento de dados necessários à definição da estratégia, como na própria divulgação dela.

As organizações estão descobrindo que a forma mais eficaz de transmitir a estratégia é usar os canais de comunicação existentes, certificando-se de que o esforço seja coordenado. Da mesma forma, não é mais possível pensar modalidades e produtos de comunicação organizacional como elementos isolados, capazes de gerar resultados independentemente. É preciso integrar as ações de comunicação e as ações estratégicas em geral.

A necessidade de revelar todos os detalhes da estratégia deve ser ponderada em relação à necessidade de manter seu caráter confidencial. A estratégia deve ser levada aos componentes da organização de uma forma tangível para que todos possam conhecê-la e trabalhar em conjunto para sua implementação. 
O verdadeiro sucesso estratégico vem quando se coloca a estratégia em prática, o que requer uma comunicação correta, o que lhe concede, definitivamente, um caráter estratégico.

\section{The strategic achievement through communication}

\section{Abstract}

This article congregates the particular visions of a Communication Planning and a Strategic Planning Management professional. It analyzes fundamental questions about the Communication role during the contemporary organization's planning process and the contribution that the strategic manager can have from communication area. In this sense, it considers the way that the information flow is organized within organizations and the manner that it helps all of its members to understand and assimilate these strategies to the organization's culture.

Keywords: Strategic communication. Strategic communication management. Communication strategic planning.

\section{Referências}

ANSOFF, H. Igor. A nova estratégia empresarial. São Paulo: Atlas, 1991.

BARRETO, Aldo de A. Visão empresarial na prática. São Paulo: Atlas, 2002.

CHIAVENATO, Idalberto; SAPIRO, Arão. Planejamento estratégico. Rio de Janeiro: Campus, 2003.

HAMEL, Gary; PRAHALAD, C. K. Competindo pelo futuro: estratégias inovadoras para obter controle do seu setor e criar os mercados do amanhã. Rio de Janeiro: Campus, 1997.

PECCHINENDA, Gianfranco. O império do instante: os novos meios de comunicação e o tempo da experiência. In: LOPES, Maria Immacolata Vassallo de; BUONANNO, Milly (Org.). Comunicação social e ética: colóquio Brasil-Itália. São Paulo: Intercom, 2005. 8 v. Coleção de Colóquios Internacionais de Comunicação.

TORQUATO, Gaudêncio. Tratado de comunicação organizacional e política. São Paulo: Thomson Pioneira, 2002. 